\title{
Differences in the Morphological Characteristics and Body Composition of Football Players FC Trepca '89 and FC Prishtina in Kosovo
}

\author{
Jovan Gardasevic ${ }^{1}$, Dusko Bjelica' ${ }^{1}$ Ivan Vasiljevic ${ }^{1}$, Sami Sermaxhaj ${ }^{2}$, Fitim Arifi \\ 'University of Montenegro, Faculty for Sport and Physical Education, Niksic, Montenegro, ${ }^{2}$ Universe College, Department of Physical Culture, Sport \\ and Recreation, Prishtina, Kosovo, ${ }^{3}$ AAB College, Faculty of Physical Education and Sport, Prishtina, Kosovo
}

\begin{abstract}
The aim of this research was to determine the differences among the top football players of the two Kosovo clubs FC Trepca ' 89 and FC Prishtina in the morphological characteristics and body composition. A sample of 35 examinees was divided into two sub-samples. The first sub-sample of the examinees consisted of 15 players of FC Trepca ' 89 of the average age $21.80 \pm 3.57$, the champions of the Kosovo Championship in the season 2016/17, while the other sub-sample consisted of 20 players of FC Prishtina of the average age of $24.30 \pm 4.99$, the vice champions of the Kosovo Championship in the season 2016/17. Football players were tested immediately after the end of the competition season 2016/17. Morphological characteristics (7) in the body composition (4) were evaluated by a battery of 11 variables: body height, body weight, waist size, triceps skin set, biceps skin set, back skin set and abdominal skin set, body mass index, fat percentage, muscle mass and bone mass. The standard central and dispersive parameters of all variables were calculated. The significance of the differences between the players of the top two football clubs in the morphological characteristics and variables for assessing body composition was determined by a t-test for independent samples. It was found that the football players of the two mentioned clubs dont have statistically significant differences by the variables that estimate the morphological characteristics and body composition.
\end{abstract}

Key words: Football, Morphological Characteristics, Body Composition

\section{Uvod}

Za fudbalsku igru se kaže da je to najvažnija sporedna stvar na svijetu, okuplja velike mase na stadionima, kraj TV ekrana (Gardašević, 2010; Gardašević, Bjelica, Popović, \& Milašinović, 2016). To je je izuzetno dinamična i brza kolektivna igra, koja bogatstvom pokreta spada u red polistrukturalnih sportskih igara (Bjelica, 2005; Gardašević i Goranović, 2011; Gardašević i Bjelica, 2013; Gardaševic \& Bjelica, 2014a; Gardasevic i Bjelica, 2014b). Fudbal je sport koga odlikuju mnogobrojne i raznovrsne složene dinamičke kineziološke aktivnosti koje se odlikuju velikim brojem cikličnih (Gardašević, Vasiljević i Bojanić, 2015; Bjelica, Popović, \& Gardašević, 2016a; Bjelica, Popović i Gardašević, 2016b; Sermax- haj, Popovic, Bjelica, Gardasevic, \& Arifi, 2017; Gardasevic, Bjelica \& Vasiljevic, 2017a; Gardasevic, Bjelica \& Vasiljevic, 2017b) i acikličnih kretanja (Gardasevic, 2015; Gardašević i sar., 2015; Gardašević, Bjelica i Vasiljević, 2016a; Gardašević, Bjelica i Vasiljević, 2016b; Gardasevic, Bjelica, Milasinovic i Vasiljevic, 2016; Gardaševic i Vasiljević, 2016; Gardasevic, Popovic, \& Bjelica, 2016). Vrhunski rezultati u fudbalu mogu se postići samo u uslovima programiranog trenažnog procesa (Gardašević, Bjelica i Popović, 2015). Od poznavanja strukture pojedinih antropoloških sposobnosti i karakteristika fudbalera, kao i njihovog razvoja, zavisi i kvalitetno upravljanje procesom sportskog treninga (Bjelica i Popović, 2012; Bjelica, 2013). Raznim istraživanjima treba utvrditi

Correspondence:

\section{Montenegro J.Gardasevic}

Gport University of Montenegro, Faculty for Sport and Physical Education, Narodne omladine bb, 81400 Niksic, Montenegro E-mail: jovan@ac.me 
određene principe i zakonitosti transformacionih procesa antropoloških karakteristika bitnih za fudbal (Gardašević, Bjelica, Georgiev, \& Popović, 2012) a među njima naravno i morfoloških karakteristika i sastava tijela. Saznanja o morfološkim karakteristikama i sastavu tijela važna su u kompleksnim sportskim igrama kao što je fudbal. Morfološki prostor definišu longitudinalna dimenzionalnost skeleta, transverzalna dimenzionalnost skeleta, masa i volumen tela (Bjelica \& Fratrić, 2011). Svrha morfoloških karakteristika je da se poboljšaju vještine u mnogim sportovima (Carter \& Heath, 1990). Morfološki statusi vrhunskih sportista su relativno homogeni, u zavisnosti od sporta, i mogu biti definisani kao modeli sportskog postignuća (Mišigoj-Duraković, Matković, \& Medved, 1995). Istraživanja morfoloških karakteristika i sastava tijela među sportistima različitih sportova ukazuje na to da sportisti različitih sportova imaju svoja specifična obilježja. Mišićna masa poboljšava sportsko postignuće u aktivnostima koje zahtevaju mišićnu snagu i izdržljivost ali i u onima koje zahtijevaju zavidnu aerobnu sposobnost (Ramadan \& Byrd, 1987; Green, 1992; Rico-Sanz, 1998). Pripadnost sportiste jednoj sportskoj grani podrazumijeva njegov biotip, koji mu daje prednost da se bavi baš tim sportom $\mathrm{u}$ odnosu na druge.

Danas je fudbal sigurno sport broj jedan u svijetu po gledanosti i popularnosti (Gardašević, Georgiev \& Bjelica, 2012; Vasiljević, Gardašević, \& Bojanić, 2013), pa samim tim i na Kosovu. Dva velika fudbalska kluba na Kosovu, koja su bila u fokusu istraživača ovog rada su FK Trepca ' 89 iz Kosovske Mitrovice i FK Pristina iz Pristine. Oni su na kraju takmičarske sezone u Kosovskoj Superligi 2016/17. zauzeli prva dva mjesta na tabeli, FK Trepca ' 89 je osvojila šampionsku titulu a FK Pristina je bila vicešampion. Po plasmanu na kraju takmičarske sezone oba ova Kluba su stekla pravo igranja na međunarodnoj fudbalskoj sceni u okviru takmičenja pod okriljem UEFA-e, pa su samim tim bili interesantni istraživačima oko utvrđivanja modelnih morfoloških karakteristika sastava tijela i njihovih međusobnih razlika.

Cilj istraživanja je bio da se analiziraju razlike u pojedinim morfološkim karakteristikama i sastavu tijela između vrhunskih fudbalera, članova FK Trepca '89 i FK Pristina, oba sa Kosova.

\section{Metod}

Podaci dobijeni u istraživanju morfoloških karakteristika i sastava tijela, kontrolisani su i pripremljeni za obradu u skladu sa postavljenim ciljem. Baze podataka su sređene po praćenim obilježjima i pripremljene za planiranu statističku obradu. Rezultati dobijeni statističkom obradom prikazani su u tabelama i analizirani po pripadajućim logičkim cjelinama. U cjelini posmatrano, prikaz rezultata istraživanja, kroz postupnost u obrazlaganju pojedinačnih veza, omogućava sagledavanje razlika u posmatranim morfološkim mjerama i sastava tijela, u skladu sa ciljem istraživanja, odnosno doprinosi jasnom određenju prema očekivanoj primjeni dobijenih rezultata u praksi. U pogledu vremenske određenosti istraživanje je transverzalnog karaktera, a sastoji se u jednokratnom mjerenju odgovarajućih morfoloških karakteristika i sastava tijela vrhunskih fudbalera seniora.

\section{Uzorak ispitanika}

Uzorak ispitanika čini ukupno 35 vrhunskih fudbalera seniorskog pogona koji nastupaju u Superligi Kosova, po- dijeljen na dva subuzorka. Prvi subuzorak su činili 15 igrača FK Trepca ' 89 iz Kosovske Mitrovice, prosječne starosti $21.80 \pm 3.57$ godina, osvajača Superlige Kosova u sezoni 2016/17. i 20 igrača FK Pristina iz Pristine, prosječne starosti $24.30 \pm 4.99$, koji su bili vicešampioni Superlige Kosova. Fudbaleri su testirani neposredno nakon okončanja takmičarske sezone 2016/17.

\section{Uzorakmjera}

Antropometrijsko istraživanje sprovedeno je uz poštovanje osnovnih pravila i principa vezanih za izbor mjernih instrumenata i tehnike mjerenja koji su standardizovani, prema upustvima Internacionalnog Biološkog Programa. Za potrebe ovog istraživanja izmjereno je 7 morfoloških mjera: visina tijela (ATV), težina tijela (ATM), obim struka (AOS), kožni nabor tricepsa (ANT), kožni nabor bicepsa (ANB), kožni nabor leđa (ANL), kožni nabor trbuha (ANS), i 4 varijable za procjenu sastava tijela: indeks tjelesne mase (BMI), procenat masti (APM), mišićna masa (AMM) i koštana masa (AKM). Za morfološko mjerenje korišteni su antropometar, kaliper i centimetarska traka. Za procjenu sastava tijela korišćena je tanita vaga, model BC-418MA. Princip rada ove vage je zasnovan na indirektnom mjerenju tjelesnog sastava, bezbjedan električni signal se šalje kroz tijelo preko elektroda smještenih u samostalnu jedinicu. Tanita vaga, zahvaljujući atletskom modu koje posjeduje, omogućava sportistima detaljno praćenje tjelesne težine, zdrastvenog stanja i kondicije, sa svim relevantnim parametrima.

\section{Metoda obrade podataka}

Podaci dobijeni istraživanjem obrađeni su postupcima deskriptivne i komparativne statističke procedure. Za svaku varijablu su obrađeni centralni i disperzioni parametri kao i mjere asimetrije i spljoštenosti. Razlike u morfološkim karateristikama i sastavu tijela fudbalera ova dva Kluba utvrđene su primjenom diskriminativne parametrijske procedure, t-testom za male nezavisne uzorke, sa statističkom značajnošću od $\mathrm{p}<0.05$.

\section{Rezultati}

U Tabelama 1 i 2 prikazani su osnovni deskriptivni statistički parametri antropometrijskih varijabli i sastava tijela fudbalera dva kluba, gdje su izračunate vrijednosti mjera centralne i disperzione tendencije i to: aritmetička sredina (Mean), standardna devijacija (Std. Dev.), varijansa (Variance), minimalne (Min) i maksimalne (Max) vrijednosti, koeficijenti zakrivljenosti (Skewness) i izduženosti (Kurtosis). Prvo su analizirani centralni i disperzioni parametri varijabli za procjenu morfoloških karakteristika i sastava tijela igrača FK Trepca '89 iz Kosovske Mitrovice (Tabela 1.).

$\mathrm{Na}$ osnovu centralnih i disperzionih parametara, vrijednosti skjunisa i kurtozisa, igrača FK Trepca '89, može se konstatovati da su sve varijable u granicama normalne raspodjele. Po vrijednosti skjunisa vidi se da je kod varijable koštana masa (AKM) došlo do male nagnutosti u stranu manjih rezultata, a isto se desilo i kod varijabli nabor bicepsa (ANB), nabor leđa (ANL) i nabor trbuha (ANS) što je dobro, jer je potkožno masno tkivo remeteći faktor za profesionalne fudbalere. Vrijednost kurtozisa kod varijable koštana masa (AKM) obrazuje leptokurtičnu krivu i pokazuje statistički značajnu izoštrenost što govori da je veliki broj rezultata $u$ ovoj varijabli raspoređen oko aritmetičke sredine, a kod va- 
Tabela 1. Centralni i disperzioni parametri varijabli za procjenu morfoloških karakteristika i sastava tijela igrača FK Trepca '89 ( $\mathrm{N}=15)$

\begin{tabular}{|c|c|c|c|c|c|c|c|c|c|}
\hline & \multirow{2}{*}{ Min } & \multirow{2}{*}{ Max } & \multirow{2}{*}{ Mean } & \multirow{2}{*}{ Std.D. } & \multirow{2}{*}{ Variance } & \multicolumn{2}{|c|}{ Skewness } & \multicolumn{2}{|c|}{ Kurtosis } \\
\hline & & & & & & Stat. & Std.E. & Stat. & Std.E. \\
\hline ATV & 174.3 & 188.0 & 181.953 & 4.4073 & 19.424 & -.502 & .580 & -.941 & 1.121 \\
\hline ATM & 66.3 & 86.1 & 76.607 & 6.7510 & 45.576 & -.066 & .580 & -1.565 & 1.121 \\
\hline AOS & 79.0 & 91.0 & 84.200 & 3.7645 & 14.171 & .182 & .580 & -.619 & 1.121 \\
\hline ANT & 3.6 & 10.5 & 7.113 & 1.8585 & 3.454 & -.114 & .580 & .094 & 1.121 \\
\hline ANB & 2.6 & 8.2 & 4.573 & 1.4864 & 2.209 & 1.015 & .580 & .957 & 1.121 \\
\hline ANL & 6.8 & 13.4 & 9.040 & 2.0743 & 4.303 & 1.192 & .580 & .333 & 1.121 \\
\hline ANS & 4.6 & 16.8 & 8.327 & 3.8401 & 14.746 & 1.391 & .580 & .702 & 1.121 \\
\hline BMI & 20.0 & 25.5 & 23.007 & 1.6520 & 2.729 & -.252 & .580 & -.762 & 1.121 \\
\hline APM & 3.8 & 14.4 & 9.807 & 2.9584 & 8.752 & -.426 & .580 & -.121 & 1.121 \\
\hline AMM & 34.9 & 43.0 & 39.020 & 2.5276 & 6.389 & -.276 & .580 & -1.124 & 1.121 \\
\hline AKM & 2.8 & 4.2 & 3.253 & .3583 & .128 & 1.194 & .580 & 2.337 & 1.121 \\
\hline
\end{tabular}

Legenda: visina tijela (ATV), težina tijela (ATM), obim struka (AOS), kožni nabor tricepsa (ANT), kožni nabor bicepsa (ANB), kožni nabor leđa (ANL), kožni nabor trbuha (ANS), i 4 varijable za procjenu sastava tijela: indeks tjelesne mase (BMI), procenat masti (APM), mišićna masa (AMM) i koštana masa (AKM)

rijabli tjelesna masa (ATM) i mišićna masa (AMM) obrazuje blagu platikurtičnost ne i statistički značajnu, što znači da postoje različiti rezultati u ovim varijablama koji nijesu raspoređeni oko aritmetičke sredine, najvjerovatnije iz razloga da po linijama tima igrači (golmani, odbrana, vezni red i napadači) imaju različitu konstituciju i samim tim različitu tjelesnu i mišićnu masu, što se i odrazilo na rezultate u ovim varijablama. Tabela 2. prikazuje centralne i disperzione parametre varijabli za procjenu morfoloških karakteristika i sastava tijela igrača FK Pristina iz Pristine.

Tabela 2. Centralni i disperzioni parametri varijabli za procjenu morfoloških karakteristika i sastava tijela igrača FK Pristina $(\mathrm{N}=20)$

\begin{tabular}{|c|c|c|c|c|c|c|c|c|c|}
\hline & \multirow{2}{*}{ Min } & \multirow{2}{*}{ Max } & \multirow{2}{*}{ Mean } & \multirow{2}{*}{ Std.D. } & \multirow{2}{*}{ Variance } & \multicolumn{2}{|c|}{ Skewness } & \multicolumn{2}{|c|}{ Kurtosis } \\
\hline & & & & & & Stat. & Std. E. & Stat. & Std. E. \\
\hline ATV & 168.0 & 188.5 & 179.725 & 5.1898 & 26.934 & -.406 & .512 & -.177 & .992 \\
\hline ATM & 63.9 & 90.1 & 75.430 & 7.8136 & 61.053 & .342 & .512 & -.609 & .992 \\
\hline AOS & 75.0 & 95.0 & 83.600 & 4.6043 & 21.200 & .246 & .512 & 1.251 & .992 \\
\hline ANT & 3.4 & 11.0 & 6.255 & 2.1659 & 4.691 & .898 & .512 & .019 & .992 \\
\hline ANB & 2.8 & 8.4 & 4.460 & 1.4332 & 2.054 & 1.655 & .512 & 2.619 & .992 \\
\hline ANL & 6.4 & 14.8 & 8.890 & 2.0264 & 4.106 & 1.382 & .512 & 2.762 & .992 \\
\hline ANS & 4.8 & 13.2 & 7.795 & 1.8878 & 3.564 & .979 & .512 & 2.310 & .992 \\
\hline BMI & 19.6 & 26.6 & 23.315 & 1.6493 & 2.720 & -.464 & .512 & .568 & .992 \\
\hline APM & 2.0 & 16.4 & 10.405 & 3.8282 & 14.655 & -.558 & .512 & -.186 & .992 \\
\hline AMM & 32.6 & 44.8 & 38.180 & 3.4567 & 11.949 & .213 & .512 & -.939 & .992 \\
\hline AKM & 2.6 & 4.3 & 3.160 & .4333 & .188 & .941 & .512 & .925 & .992 \\
\hline
\end{tabular}

Na osnovu centralnih i disperzionih parametara, vrijednosti skjunisa i kurtozisa igrača FK Pristina, može se konstatovati da su sve varijable u granicama normalne raspodjele $\mathrm{i}$ da su vrijednosti vrlo slične fudbalerima FK Trepca '89. Takođe se može konstatovati da su igrači FK Trepca ' 89 u prosjeku mlađi, visočiji i teži od igrača FK Pristina, kao i da imaju veće vrijednosti svih kožnih nabora istina neznatno, međutim da li i statistički značajno to će pokazati komparativna statistička procedura, t-test (Tabela 3.). Po vrijednosti skjunisa vidi se da je kod varijabli nabor bicepsa (ANB) i nabor leđa (ANL) došlo do male nagnutosti u stranu manjih rezultata što je dobro jer je potkožno masno tkivo remeteći faktor za profesionalne fudbalere. Vrijednosti kurtozisa kod varijable obim struka (AOS) obrazuje blagu leptokurtičnu krivu što govori o priličnoj ujednačenosti igračkog kadra FK Pristina u ovoj varijabli, a kod tri varijable nabor bicepsa (ANB), nabor leđa (ANL) i nabor trbuha (ANS) obrazuje leptokurtične krive i pokazuje statistički značajnu izoštrenost što govori da je veliki broj rezultata u ovim varijablama raspoređen oko aritmetičke sredine. Da bi se utvrdilo da li ima statistički značajne razlike $\mathrm{u}$ analiziranim varijablama kod vrhunskih fudbalera ova dva Kluba sa Kosova, koji je se takmiče u tamošnjoj Superligi, primjenjena je statistička procedura t-test za male nezavisne uzorke (Tabela 3.).

$\mathrm{Na}$ osnovu dobijenih vrijednosti rezultata t-testa, može se primijetiti da ne postoje statistički značajne razlike ni kod jedne analizirane varijable na nivou značajnosti $p<0.05$. Uvidom u poslednju kolonu (Mean difference) može se konstatovati da fudbaleri FK Trepca ' 89 iz Kosovske Mitrovice, koji su završili sezonu u Kosovskoj Superligi na prvom mjestu, imaju manji indeks tjelesne mase, manji procenat masti i veću mišićnu masu od fudbalera FK Pristine iz Pristine, što je i poželjno, ali ne i statistički značajnu. Na drugoj strani, fudbaleri FK Pristina imaju manje vrijednosti kožnih nabora kojima se procjenjuje potkožno masno tkivo što je remetilački faktor za fudbalere, ali i ova razlika nije statistički značajna. 
Tabela 3. Vrijednosti t-testa izmedju aritmetičkih sredina varijabli za procjenu morfoloških karakteristika i sastava tijela igrača FK Trepca '89 (N=15) i FK Pristina (N=20)

\begin{tabular}{|c|c|c|c|c|c|c|c|}
\hline Varijable & Klub & Mean & Std. D. & Std. E. M. & t-test & Sig. & $\begin{array}{c}\text { Mean } \\
\text { Difference }\end{array}$ \\
\hline \multirow{2}{*}{ ATV } & TRE & 181.953 & 4.4073 & 1.1380 & \multirow{2}{*}{1.339} & \multirow{2}{*}{.190} & \multirow{2}{*}{2.2283} \\
\hline & PRI & 179.725 & 5.1898 & 1.1605 & & & \\
\hline \multirow{2}{*}{ ATM } & TRE & 76.607 & 6.7510 & 1.7431 & \multirow{2}{*}{.467} & \multirow{2}{*}{.644} & \multirow{2}{*}{1.1767} \\
\hline & PRI & 75.430 & 7.8136 & 1.7472 & & & \\
\hline \multirow{2}{*}{ AOS } & TRE & 84.200 & 3.7645 & .9720 & \multirow{2}{*}{.412} & \multirow{2}{*}{.683} & \multirow{2}{*}{.6000} \\
\hline & PRI & 83.600 & 4.6043 & 1.0296 & & & \\
\hline \multirow{2}{*}{ ANT } & TRE & 7.113 & 1.8585 & .4799 & \multirow{2}{*}{1.231} & \multirow{2}{*}{.227} & \multirow{2}{*}{.8583} \\
\hline & PRI & 6.255 & 2.1659 & .4843 & & & \\
\hline \multirow{2}{*}{ ANB } & TRE & 4.573 & 1.4864 & .3838 & \multirow{2}{*}{.228} & \multirow{2}{*}{.821} & \multirow{2}{*}{.1133} \\
\hline & PRI & 4.460 & 1.4332 & .3205 & & & \\
\hline \multirow{2}{*}{ ANL } & TRE & 9.040 & 2.0743 & .5356 & \multirow{2}{*}{.215} & \multirow{2}{*}{.831} & \multirow{2}{*}{.1500} \\
\hline & PRI & 8.890 & 2.0264 & .4531 & & & \\
\hline \multirow{2}{*}{ ANS } & TRE & 8.327 & 3.8401 & .9915 & \multirow{2}{*}{.540} & \multirow{2}{*}{.593} & \multirow{2}{*}{.5317} \\
\hline & PRI & 7.795 & 1.8878 & .4221 & & & \\
\hline \multirow{2}{*}{ BMI } & TRE & 23.007 & 1.6520 & .4266 & \multirow{2}{*}{-.547} & \multirow{2}{*}{.588} & \multirow{2}{*}{-.3083} \\
\hline & PRI & 23.315 & 1.6493 & .3688 & & & \\
\hline \multirow{2}{*}{ APM } & TRE & 9.807 & 2.9584 & .7639 & \multirow{2}{*}{-.503} & & \\
\hline & PRI & 10.405 & 3.8282 & .8560 & & .619 & -.5983 \\
\hline AMM & TRE & 39.020 & 2.5276 & .6526 & 794 & 433 & 8400 \\
\hline AIVIVI & PRI & 38.180 & 3.4567 & .7730 & .174 & בכדי. & .0400 \\
\hline$\triangle K M M$ & TRE & 3.253 & .3583 & .0925 & & & \\
\hline AKM & PRI & 3.160 & .4333 & .0969 & $.6 / 8$ & .503 & .0933 \\
\hline
\end{tabular}

\section{Diskusija}

Cilj ovog istraživanja je bio da se utvrdi razlika u varijablama za procjenu morfoloških karakteristika i sastava tijela vrhunskih igrača dva fudbalska kluba sa Kosova, FK Trepca ' 89 iz Kosovske Mitrovice i FK Pristina iz Pristine, koji su zauzeli prva dva mjesta u Kosovskoj fudbalskoj Superligi u takmičarskoj sezoni 2016/17. Uzorak od ukupno 35 ispitanika je podijeljen na dva subuzorka. Prvi subuzorak ispitanika su činili 15 igrača FK Trepca ' 89 prosječne starosti $21.80 \pm 3.57$ godina osvajača fudbalskog Prvenstva Kosova u sezoni 2016/17, a drugi subuzorak su činili 20 igrača FK Pristina prosječne starosti $24.30 \pm 4.99$, koji su zauzeli drugo mjesto u pomenutoj sezoni. Rezultati su dobijeni korišćenjem baterije od 11 testova u prostoru morfoloških karakteristika i sastava tijela. Uvidom u osnovne deskriptivne statističke parametre se može zaključit da se radi o profesionalnim sportistima. Vrlo slične rezultate u varijablama za procjenu morfoloških karakteristika i sastava tijela su dobili istraživači koji su analizirali igrače najboljih fudbalskih klubova u Bosni i Hercegovini (Corluka et al., 2018), kao i u Crnoj Gori (Corluka \& Vasiljevic, 2018; Gardasevic, Bjelica, Popovic, Vasiljevic, \& Milosevic, 2018; Bjelica, Gardasevic, \& Vasiljevic, 2018). Vidi se da su igrači oba kluba približnih srednjih vrijednosti analiziranih varijabli, što i ne čudi jer se radi o dva vrhunska kluba na Kosovu gdje je i velika koncentracija dobrih igrača. Rezultati t-testa su pokazali da ne postoje statistički značajne razlike ni kod jedne varijable, pa se može zaključiti da su igrači oba kluba približnih srednjih vrijednosti analiziranih varijabli za procjenu morfoloških karakteristika i sastava tijela. Kod varijabli kožnih nabora, koje procjenjuju potkožno masno tkivo, srednje vrijednosti su veće kod igrača FK Trepca '89, istina ne i statistički značajno, što može poslužiti trenerima FK Trepca ' 89 da se baziraju na radu koji će omogućiti redukciju istog, i sigurno da će time svoje fudbalere napraviti još boljim i uspješnijim, jer je to remeteći faktor za fudbal. Treneri u FK Pristina zajedno sa klupskim nutricionistom treba da povedu računa o redukciji procenata masti kod svojih igrača. Takođe, u FK Pristina trebali bi se posvetiti i drugim istraživanjima i provjeriti stanje funkcionalno-motoričkog statusa, psihološke pripreme kao i taktičke obučenosti svojih igrača i analizirati da li tu leži razlog slabijeg rezultata u prvenstvenoj trci u odnosu na FK Trepca '89. Rezultati koji su dobijeni ovim istraživanjem mogu poslužiti kao modelni parametri u procjenjivanim varijablama za sve ostale igrače fudbalskih klubova na Kosovu, jer analizirani fudbaleri su bili najbolji i najuspješniji u Kosovskoj Superligi na kraju takmičarske sezone 2016/17.

\section{Acknowledgements}

There are no acknowledgements.

\section{Conflict of Interest}

The authors declare that there are no conflict of interest.

Received: 15 May 2018 | Accepted: 22 June 2018 | Published: 13 July 2018

\section{References}

Bjelica, D. (2005). Sistematizacija sportskih disciplina i sportski trening. Podgorica: Crnogorska sportska akademija.

Bjelica, D., \& Fratrić, F. (2011). Sportski trening: teorija, metodika i dijagnostika. Nikšić: Fakultet za sport i fizičko vaspitanje.

Bjelica, D., i Popović, S. (2012). Fudbal-teorija, tehnika i taktika. Podgorica: Crnogorska sportska akademija.

Bjelica, D., Popovic, S., Kezunovic, M., Petkovic, J., Jurak, G., \& Grasgruber, P. (2012). Body Height and Its Estimation Utilizing Arm Span Measurements in Montenegrin Adults. Anthropological Notebooks, 18(2):69-83.

Bjelica, D. (2013). Teorija sportskog treninga. Podgorica: Univerzitet Crne Gore.

Bjelica, D., Popović, S., i Gardašević, J. (2016a). Modeli fizičke pripreme vr- 
hunskih sportaša i doziranje opterećenja. Zbornik radova 14.godišnje međunarodne konferencije "Kondicijska priprema sportaša" (185-189), Zagreb: Udruga kondicijskih trenera Hrvatske.

Bjelica, D., Popović, S., i Gardašević, J. (2016b). Opći principi planiranja i programiranja fizičkih priprema sportaša. Zbornik radova 14.godišnje međunarodne konferencije "Kondicijska priprema sportaša" (190-192), Zagreb: Udruga kondicijskih trenera Hrvatske.

Bjelica, D., Gardasevic, J., \& Vasiljevic, I. (2018). Differences in the morphological characteristics and body composition of football players FC Sutjeska and FC Mladost in Montenegro. Journal of Anthropology of Sport and Physical Education, 2(2), 31-35. doi: 10.26773/jaspe.180406

Carter, J.E.L., \& Heath, B.H. (1990). Somatotyping-Development and application. Cambridge, United Kingdom: Cambridge University Press.

Corluka, M., \& Vasiljevic, I. (2018). Differences in the morphological characteristics and body composition of football players in Montenegro. Journal of Anthropology of Sport and Physical Education, 2(1), 3-7. doi: 10.26773/ jaspe. 180101

Corluka, M., Bjelica, D., Vasiljevic, I., Bubanja, M., Georgiev, G., \& Zeljko, I. (2018). Differences in the morphological characteristics and body composition of football players of HSC Zrinjski Mostar and FC Siroki Brijeg in Bosnia and Herzegovina. Sport Mont, 16(2), 77-81. doi: 10.26773/ smj.180614

Gardašević, J. (2010). Efekti programiranog rada u pripremnom periodu na transformaciju bazično-motoričkih i situaciono-motoričkih sposobnosti kod fudbalera kadetskog uzrasta. Neobjavljena magistarska teza. Nikšić: Fakultet za sport i fizičko vaspitanje.

Gardašević, J., i Goranović, K. (2011). Efekti programiranog rada u pripremnom periodu na transformaciju eksplozivne snage kod fudbalera kadeta. Sport Mont, IX(28-30), 55-62.

Gardašević, J., Georgiev, G., \& Bjelica, D. (2012). Qualitative changes of basic motor abilities after completing a six-week training programme. Acto Kinesiologica, 6(1), 70-4.

Gardašević, J., Bjelica, D., Georgiev, G., \& Popović, S. (2012). Transformation of situational motor abilities with football players-cadets. Proceeding book, XVI International Scientific Congress "Olympic Sports and Sport for All" \& VI International Scientific Congress „Sport, Stress, Adaptation" (373-377), Sofia: National Sports Academy "Vassil Levski".

Gardašević, J., i Bjelica, D. (2013). Efekti programiranog trenažnog rada u trajanju od šest nedjelja na transformaciju fleksibilnosti kod fudbalera kadetskog uzrasta. Sport Mont, 11(37-39), 212-7.

Gardaševic, J., \& Bjelica, D. (2014a). The effects of the training in the pre paration period on the dribbling speed with fifteen years old football players. Book of Abstracts of the 11th International Scientific Conference on Transformation Process in Sport "Sport Performance" (22-23), Podgorica: Montenegrin Sports Academy.

Gardasevic, J., i Bjelica, D. (2014b). Efekti rada u pripremnom periodu na brzinu vođenja lopte petnaestogodišnjih fudbalera. Sport Mont, 12(40-42), 160-6.

Gardašević, J., Vasiljević, I., \& Bojanić, D. (2015). Six-week preparation period and its effects on coordination transformation with football players under 16. Book of Abstracts 11th International Scientific Conference Ma nagement, Sport, Olympism (36), Beograd: Fakultet za menadžment u sportu, Alfa univerzitet.

Gardasevic, J. (2015). The effects of the training in the preparation period on the agility transformation with cadet level football players. Book of Abstracts of the 12th International Scientific Conference on Transformation Process in Sport "Sport Performance" (76-77), Podgorica: Montenegrin Sports Academy.

Gardašević, J., Vasiljević, I., Bojanić, D., Muratović, A., Ljubojević, M., Milašinović, R., \& Bubanja, M. (2015). Six-week Preparation Period and its Effects on Transformation Movement Speed with Football Players Under 16.
Book of Abstracts, International Scientific Conference "Effects of Physical Activity Application to Anthropological Status with Children, Youth and Adults" (148), Belgrade:University of Belgrade: Faculty of Sport and Physical Education.

Gardašević, J., Bjelica, D., i Popović S. (2015). Efekti programiranog rada tokom pripremnog perioda na transformaciju agilnosti kod fudbalera kadetskog uzrasta. Sport Mont, 13(43-45), 355-60.

Gardašević, J., Bjelica, D., \& Vasiljević, I. (2016a). Six-Week Preparation Period and its Effects on Transformation Movement Speed with Football Players Under 16. Sport Mont, 14(1), 13-6.

Gardašević, J., Bjelica, D., \& Vasiljević, I. (2016b). The Effects of the Training in the Preparation Period on the Repetitive Strength Transformation With Cadet Level Football Players. Book of Abstracts of the 13th International Scientific Conference on Transformation Processes in Sport "Sport Performance" (43), Podgorica: Montenegrin Sports Academy.

Gardasevic, J., Bjelica, D., Milasinovic, R., \& Vasiljevic, I. (2016). The Effects of the Training in the Preparation Period on the Repetitive Strength Transformation with Cadet Level Football Players. Sport Mont, 14(2), 31-3.

Gardaševic, J., \& Vasiljević, I. (2016). Effects of Preparation Period on Endurance in U16 Football Players. Book of Abstracts of the $4^{\mathrm{TH}}$ International Scientific Conference "Exercise and Quality of Life" (108), Novi Sad: University of Novi Sad, Faculty of Sport and Physical Education.

Gardašević, J., Bjelica, D., Popović, S., \& Milašinović, R. (2016). Preparation Period and its Effects on the Speed of Ball Leading at Players U16. In Book of Summaries of 11th FIEP European Congress "Anthropological Aspects of Sport, Physical Education and Recreation" (30-31), Banjaluka: University of Banjaluka, Faculty of Physical Education and Sport.

Gardasevic, J., Popovic, S., \& Bjelica, D. (2016). After preparation period ball shooting accuracy at players U15. In Abstract Book of the 8th Conference for Youth Sport (88), Ljubljana: University of Ljubljana, Faculty of Sport.

Gardasevic, J., Bjelica, D., \& Vasiljevic, I. (2017a). The strength of kicking the ball after preparation period with $\mathrm{U} 15$ football players. Book of Abstracts of the 14th International Scientific Conference on Transformation Processes in Sport "Sport Performance" (65-66), Podgorica: Montenegrin Sports Academy.

Gardasevic, J., Bjelica, D., \& Vasiljevic, I. (2017b). The Strength of Kicking the Ball after Preparation Period with U15 Football Players. Sport Mont, 15(2), 39-42.

Gardasevic, J., Bjelica, D., Popovic, S., Vasiljevic, I., \& Milosevic, Z. (2018). Differences in the morphological characteristics and body composition of football players FC Buducnost and FC Mladost in Montenegro. Journal of Anthropology of Sport and Physical Education, 2(1), 51-5. doi: 10.26773/jaspe.180109

Green, S. (1992). Anthropometric and physiological characteristics of south Australian soccer players. Australian Journal of Science and Medicine in Sport, 24, 3-7.

Mišigoj-Duraković, M., Matković, B., \& Medved, R. (1995). Morfološka antropometrija u športu. Morphological anthropometry in sports. Zagreb, Croatia: Fakultet za fizičku kulturu.

Ramadan, J., \& Byrd, R. (1987). Physical characteristics of elite soccer players. Journal of Sports Medicine and Physical Fitness, 27, 424-8.

Rico-Sanz, J. (1998). Body composition and nutritional assessments in soccer. International Journal of Sport Nutrition, 8, 113-23.

Sermaxhaj, S., Popovic, S., Bjelica, D., Gardasevic, J., \& Arifi, F. (2017). Effect of recuperation with static stretching in isokinetic force of young football players. Journal of Physical Education and Sport, 17(3), 1948-53. doi: 10.7752/jpes.2017.03191

Vasiljević, I., Gardašević, J., i Bojanić, D. (2013). Uporedna analiza motoričkog prostora između aktivnih fudbalera kadetskog uzrasta i učenika srednje škole. Zbornik naučnih i stručnih radova VI međunarodni simpozijum "Sport i zdravlje" (212-215), Tuzla: Fakultet za tjelesni odgoj i sport. 